\title{
SUBSÍDIOS PARA UMA REFLEXÃO ACERCA DA APLICAÇÃO DE RESULTADOS DE PESQUISAS PELO ENFERMEIRO ASSISTENCIAL*
}

\author{
Creso Machado Lopes**
}

RESUMO - Estudo realizado junto a enfermeiros assistenciais do Rio de Janeiro, com objetivo de questionar a aplicação de resultados de pesquisas e levantar as facilidades e dificuldades. Utilizamos um roteiro de entrevistas para coletar os dados. Os resultados evidenciam que eles vêm aplicando os resultados de pesquisas apesar das limitações.

ABSTRACT - A study was carried out on care-providing nurses in Rio de Janeiro in order to question the application of research results and to survey the facilities and dificulties. Data were collected using an interview form. The results show that nurses are applying the results of research despite the limitations.

\section{INTRODUÇÃO}

Nos países desenvolvidos e em fase de desenvolvimento o enfermeiro, de modo geral, vem atuando de forma eficiente no processo de pesquisa, obtendo consideráveis resultados.

KRUEGER (1978), afirma que nos Estados Unidos, nos últimos 15 anos considerável atenção e recursos financeiros têm sido destinados para o incentivo da pesquisa em enfermagem, enquanto menor atenção é dada à aplicação dos resultados.

No Brasil, as recomendações dos Congressos Brasileiros de Enfermagem enfatizam o desenvolvimento da pesquisa pelo enfermeiro e recomendam às instituições de ensino que despertem nos estudantes $o$ interesse pela pesquisa.

Para CIANCIARULLO (1979), no Brasil, “além do mito de que os enfermeiros não têm tradição em pesquisa há também um hiato entre o desenvolvimento teórico e a operacionalização institucional, com o objetivo de refletir na prática a produtividade do modelo ou estilo teórico",

Convém salientar que a falta de atenção dada aos resultados de pesquisas já ef etuadas pode ser representada como uma limitação ao desenvolvimento da própria prática de enfermagem, além do fato de que a utilização desses resultados seja razoavelmente nova na enfermagem.

LAZARFELD \& SIEBER apud KETEFIAN (1975) também afirmam que a falta de interesse em pesquisa desanima novos esforços e que os resultados não implementados não podem ser avaliados; assim sendo, os pesquisadores permanecerão ignorando a utilidade de seus trabalhos e também os que praticam a enfermagem tendem a permanecer céticos.

Neste contexto, PADILLA (1979) afirma que o espaço existente entre a introdução do modelo escrito e sua operacionalização tem sido uma ponte difícil. É amplamente conhecido esse espaço entre o resultado da pesquisa e sua aplicação na prática de enfermagem, sendo esse assunto cuidadosamente documentado também por NOTTER (1973) e KETEFIAN (1975).
Assim sendo, a pesquisa às vezes é tida como um fim em si mesma, isto é, seus resultados não estão sendo aplicados na prática. Diante de tal situação, os pesquisadores sentem-se frustrados pois importantes achados não estão sendo utilizados na prática.

Desta forma, LOPES (1983) menciona que os enfermeiros assistenciais consideram que os resultados encontrados não têm sido transferidos para a prática, não trazendo nenhuma melhoria para o paciente e para a instituição e poucos são os benefícios trazidos para a categoria de enf ermeiros e à comunidade.

Um outro aspecto que deve ser levado em consideração, conforme cita ALMEIDA (1985), é que “ $a$ pesar de serem muitas as expressões relacionadas com a aplicação dos resultados das pesquisas, estas continuam tendo pouca influência na prática de enfermagem".

Assim STETLER \& MARRAN apud ALMEIDA (1985) "ao referirem-se a esta situação, dizem que uma das razões que concorrem para este fato é que embora conhecendo várias maneiras de ajudar os enfermeiros assistenciais a avaliarem o potencial de uma pesquisa, não se têm elaborado critérios sistemáticos para avaliar sua aplicabilidade. Sugerem os autores que antes do enfermeiro decidir pela modificação de sua prática, aplicando os resultados de uma pesquisa, ele deverá passar por três fazes do pensamento crítico: - determinação do potencial da pesquisa, ou seja, a sua validaçẫo; - determinação da qualidade e aplicação prática da mesma (avaliação comparada); $e-d e-$ finição da utilização (tomada de decisões)".

Assim esses autores mencionam que seria recomendável que o enfermeiro ao tentar implementar os resultados de uma pesquisa, talvez devesse ter uma base teórica para as ações a que está se propondo; questionar-se até que ponto a aplicação dos resultados de uma pesquisa implementada num novo programa assistencial pode interferir na política de ação da instituição para mudanças, se os riscos para o cliente serão de ordem física ou psicológica; para o enf ermeiro estes riscos serão de ordem legal ou de natureza diversa e para os demais elementos da equipe os mesmos

\footnotetext{
* Trabalho apresentado à disciplina Metdologia da Pesquisa em Enfermagem do Curso de Pós-Graduaçao da EESP-USP.

** Professor Adjunto do Curso de Enfermagem - Univeridade Federal do Acre. Enfermeiro do PAM - INAMPS - ACRE.
} 
serão de ordem psicológica ou social.

OLIVEIRA (1985) menciona que "como se está procurando a incorporação dos resultados à prática profisssional, sem dúvida, a transferência do saber adquirido pela pesquisa a essa prática demandará tempo e concentrado esforço".

Neste contexto, CASTRO et alii (1985) afirmam que "as dificuldades para conhecer ou aplicar os resultados de pesquisas prendem-se a vários pontos: a falta de hábito de ler; falta de segurança para avaliar a qualidade dos resultados e a falta de intercâmbio de informações na enfermagem constitui-se em obstáculo tanto para conhecer como para aplicar os resultados de pesquisa. Concluem, diante de tantos e tão variadas dificuldades que não é surpreendente a não aplicação de resultados de pesquisa na prática".

\section{OBJETIVOS}

Para o desenvolvimento do trabalho estabelecemos os seguintes objetivos:

Questionar a aplicação dos resultados de pesquisas realizadas pelo enfermeiro assistencial, no seu campo prático.

Levantar as facilidades e dificuldades encontradas pelo enfermeiro aasistencial, ao aplicar resultados de suas pesquisas.

\section{METODOLOGIA}

\section{População}

A população de nosso estudo foram os enfermeiros assistenciais da cidade do Rio de Janeiro, autores e co-autores que publicaram artigos na Revista Brasileira de Enfermagem no período de 1960 a 1985 e na revista Paulista de Hospitais de 1960 a 1979 (período até a época da realização deste estudo).

\section{Técnica de coleta de dados}

Para a técnica de coleta de dados fizemos uso de entrevistas, as quais foram informais, abertas, não utilizamos nenhum método estatístico para a seleção amostral. Estas foram efetuadas de acordo com a aceitação e tempo livre dos entrevistados.

Antes de iniciarmos as entrevistas, fazíamos nossa apresentação e solicitávamos a sua participação.

As entrevistas foram gravadas, o tempo variou de 20 a 40 minutos, fizemos uso de um "Roteiro para entrevista", onde tivemos o cuidado de garantir o anonimato dos entrevistados.

Após as entrevistas, as gravações foram transcritas literalmente, extraídos os conteúdos, estes foram analisados e discutidos.

\section{RESULTADOS E DISCUSSÃO}

Dentre as duas revistas por nós levantadas encontramos um total de 20 artigos, sendo $12(60 \%)$ na Revistra Brasileira de Enfermagem e $8(40 \%)$ na Revista Paulista de Hospitais.

Desses 20 artigos publicados, entre autores e coautores, encontramos um total de 24 enfermeiros assistenciais, e através das entrevistas contactamos com
12 deles, ou sejam, 50\%. Por ser um período longo de publicações, representando 26 anos, alguns colegas haviam viajado; mudado de emprego, estado ou se aposentado e outros já eram falecidos.

Com relação às áreas de publicações, 6 (30\%) pertenciam à Enfermagem Cirúrgica; 4 (20\%) à Enfermagem Médica; 4 (20\%) à Administração em Enfermagem; 4 (20\%) em Saúde Pública; 1 (5\%) à Enfermagem Pediátrica e $1(5 \%)$ apenas analisa a profissão.

Das publicações mencionadas, 9 artigos referiamse à década de $60 ; 10$ à de $70 \mathrm{e} 1$ à de 80 . Nessa última verificamos uma baixa freqüência, pelo fato de só termos feito o levantamento na Revista Paulista de Hospitais no período de 1960 a 1979.

Após os comentários e análises metodológicas, passamos agora ao conteúdo das entrevistas, os quais serão apresentados sob os pontos de vista descritivo e qualitativo, com base na seqüência do roteiro das entrevistas.

As questões formuladas apresentam-se assim:

1. "Como você vê a aplicação de resultados de pesquisas realizadas pelo enfermeiro assistencial?"

As respostas indicam que essa aplicação é importante e fundamental para o crescimento da enfermagem; vêem-na de forma positiva pelo fato de estarem mais perto do paciente, por vivenciarem o campo prático e acreditarem que seriam as pessoas mais indicadas para a utilização dos resultados de pesquisa.

Mencionaram que temos por obrigação valorizar trabalhos de colegas, pois esses são feitos em cima de suas vivências e experiências práticas.

Ao ef etuarmos nossas entrevistas, encontramos resultados históricos da evolução da pesquisa em enfermagem, assim apresentados: que por volta de 1964, o início da pesquisa no seu serviço foi muito importante, e que, é claro, na época já se fazia pesquisa, não com a sistematização atual, mas de forma "aleatória". Creio que aqui há a referência da não utilização do "mótodo estatístico" definido, pois no início elas estavam mais voltadas para administração, gerência e a supervisão do serviço de enfermagem.

Mencionaram também que os próprios Congressos Brasileiros de Enfermagem e a Revista Brasileira de Enfermagem davam incentivos e subsídios à produção e aplicação de resultados de pesquisas.

Outros nos informaram que por volta de 1975/76, a enfermagem estava tentando se estabelecer como ciência, sistematizando seus conhecimentos, desenvolvendo as bases da metodologia da assistência de enfermagem. Com isso houve uma melhoria no conhecimento produzido, época em que citaram, inclusive, o surgimento das Revistas "Enfermagem em Novas Dimensões" e "Enfermagem Atual".

Alguns entrevistados mencionaram que mesmo estando mais voltados para a área de administração têm visto que o enfermeiro assistencial vem aplicando resultados de pesquisas e que esta ênfase, atualmente, vem sendo dada nos próprios currículos de enfermagem.

Um outro grupo de enfermeiros nos informou que tem havido pouca aplicação de resultados de pesquisas, pois o próprio profissional recebe e não lê as revistas; não demonstram interesse ao que se produz alegando falta de tempo, sobrecarga de trabalho e 
ocupação com outras atividades que não a sua.

Aliado a isso, em nosso estudo encontramos que ao questionarmos se os enfermeiros assistenciais "tem $o$ hábito de lerem as publicações que recebem", 41 (52,56\%) "lêem"; 17 (21,80\%) "não lêem" e 20 $(25,64 \%)$ "lêem em parte". Estes dados refletem que o resultado encontrado na questão seguinte "têm acompanhado os trabalhos de pesquisa em enfermagem no Brasil?" onde apenas $4(5,12 \%)$ referiram "acompanhar”, $35(44,88 \%)$ "não" e $39(50,00 \%)$ "acompanham em parte".

Esses dados são semelhantes aos encontrados por CASTRO et alii (1985) e por BARNETT (1981), onde constatam que os enfermeiros lêem muito pouco e que não isentam de culpa os administradores que não proporcionam condições favoráveis para utilização de resultados de pesquisas.

Esses dados acima também vêem ao encontro ao referido por uma colega que foi membro da diretoria da ABEn-RJ, quando mencionou que os associados não iam nem buscar as suas revistas, daí não crer muito na aplicação de resultados, porque se o pessoal desconhece, como vai aplicar?

Outras informações também foram levantadas: quando o enfermeiro assistencial sai para fazer curso de especialização ou outro, geralmente com o seu retorno não há aplicação do trabalho desenvolvido no curso. Esta situação pode acontecer em decorrência de: o próprio enfermeiro não transmitir bem sua pesquisa ou o trabalho não é pertinente à dinâmica do serviço de enfermagem em que atua. Acontece também que o enfermeiro, às vezes, faz um trabalho individual e não de conhecimento coletivo e tudo isso tem gerado dificuldades na sua incorporação à prática.

Não faltaram críticas à dicotomia entre ensino e serviço, e até existe uma crença de que o docente é muito mais capaz que o enfermeiro assistencial, fato evidenciado no hospital de ensino e, muitas vezes, ele até incorpora a consciência de que ele não é tão capaz e que pesquisa não é assunto para ele.

Prosseguindo nosso estudo, a segunda questão apresentada foi: 2. "'Que aspectos devem ser levados em consideração ao se aplicar resultados dessas pesquisas?'"

As respostas obtidas foram que o enfermeiro assistencial deve ser incentivado; receber treinamento em pesquisa e apoio do pessoal docente; interessar-se pela pesquisa; receber colaboração dos colegas, da chefia de enfermagem, como também da direção do hospital.

Responderam que seus trabalhos devem ser mais objetivos, de acordo com as estruturas dos órgãos, condições físicas, materiais e pessoais, pois disseram que os trabalhos têm sido muito didáticos e não viáveis de aplicção no local de trabalho.

Citaram que os trabalhos devem ser divulgados em congressos, reuniões internas, seminários, encontros regionais para que seus resultados possam ser discutidos e aplicados por colegas.

Para eles, a pesquisa tem realmente que ser comprovada, fundamentada e levar em consideração a validade do trabalho para poder ser aplicada. Também disseram que ao se aplicar um resultado de pesquisa, deve-se procurar saber quem foi o autor, se o trabalho tem fonte digna, qual a confiabilidade do mesmo, para não se correr o risco de utilizar um dado não funda- mentado.

A esse respeito ALMEIDA (1985) diz que " $a$ aplicação dos resultados de uma pesquisa deve ser fundamentada em critérios válidos de estudo. Par isso, é necessário um estudo cuidadoso das pesquisas, questionando cada argumento do autor, seus resultados $e$ conclusões".

CASSIANI (1987) em seu estudo sobre coleta de dados nas pesquisas em enfermagem apresenta uma contribuição a respeito das estratégias, validade e confiabilidade. Cremos que tanto os produtores com os consumidores de pesquisas deveriam tomar conhecimentos destes aspectos relevantes.

A terceira questão foi: 3 . "'A pesquisa realizada pelo enfermeiro assistencial tem mais chance de aplicação do que a do enf ermeiro docente?"

Para aqueles que disseram "sim", a justificativa é o fato de estarem no dia-a-dia do serviço de enfermagem, por terem o material humano às mãos (paciente), sentirem o doente mais de perto e por estar vendo, fazendo, acompanhando e tirando conclusões.

Para as respostas "não", apontaram que esse argumento não é válido, que não vêem assim, pois depende de cada pesquisa, e o que basta é o pesquisador convencer em seus argumentos e fazer a divulgação.

Um outro fator negativo, está relacionado à dicotomia entre ensino e serviço, entre o docente e o assistencial. Diante disso, foi mencionado que o aluno de graduação ao chegar ao campo já apresenta um preconceito muito grande em relação ao enfermeiro assistencial. Ele pensa que o enfermeiro docente é quem faz pesquisa, quem sabe mais, quem aplica resultados e depois que ele começa a entrar em contato com o pessoal da área assistencial passa a sentir a sua potencialidade.

Citaram que essa discriminação também está relacionada ao salário, carga horária de trabalho, e que o enfermeiro de hospital universitário também deveria ser docente e sugeriram uma troca, um período o enfermeiro assistencial ficaria ligado ao ensino e num outro ao campo; também deveria acontecer o mesmo com o docente, pois o que falta ao assistencial é a teoria e ao docente a prática de campo.

Em nossa opinião, o atual sistema de saúde, educacional e econômico do país não permite essa rotatividade de trabalho. O próprio sistema de integração docente-assistencial parece não correspónder à espectativa como também não vem sendo desenvolvido na prática. Assim, acreditamos que deva haver um maior amadurecimento ou abertura entre o ensino e serviço para que surjam modelos que se adequem às necessidades e condições de cada um.

Prosseguindo, encontramos afirmações que o professor também tem possibilidade de aplicar os resultados de suas pesquisas ao ensino, não só por estar voltado à docência, mas porque ele tem interesse em mostrar aos seus alunos a possibilidade de aplicação. Com isso acreditam que as pesquisas deles estão muito dirigidas ao seu próprio aluno, ligado à área de ensino, ao método, com forma de melhorar essa parte do aluno.

Já os que responderam "em parte", assim se manif estaram por afirmarem que depende da direção do trabalho proposto por cada um, se ele for direcionado para a área assistencial o enfermeiro terá maior facilidade para desenvolvê-lo. 
Acreditam também que se o tema escolhido pelo enfermeiro não fizer parte do projeto do serviço de enfermagem, se for um trabalho individual e não tiver apoio da administração do hospital, não possuir recursos humanos e materiais necessários, haverá dificuldades na aplicação de seus resultados.

Para os que mencionaram serem "iguais", eles sentem que há ocorrência desde que o docente atue em campo.

Finalizando este aspecto, alguns informaram que não é que teriam mais chance e sim que ao se fazer um trabalho em cima do que se está vivenciando, procurase um enfoque mais prático e quando se faz uma pesquisa "tirada" de livros, as coisas ficam muito teóricas, distantes da prática.

A quarta questão apresentada: 4. "No seu entender, quais são as facilidades e dificuldades encontradas pelo enfermeiro assistencial ao resultados de suas pesquisas?"'

As "facilidades" por eles mencionadas foram: disponibilidade de recursos humanos, planta física, treinamento em serviço, campo amplo por estarem frente ao trabalho e em contato com o doente, mais chance para observarem resultados do seu trabalho e de colegas, facilidade de desenvolver suas habilidades técnicas, veículo condutor da assistência de enfermagem.

Responderam que ao desenvolver um trabalho de pesquisa as ajudas são imensas, as pessoas até se aproximam no sentido de "lhes empurrarem", e que o fato de você escolher um tema voltado para a situação de trabalho contribui para sua aplicação.

A esse respeito ALMEIDA (1985) em seu estudo encontrou que dos 45 enfermeiros entrevistados, das mais diferentes formações; procedências; área de atuação, Estados, 19 (42,2\%) opinaram sentir-se seguros para aplicar na prática profisssional os resultados das pesquisas em enfermagem, assim justificados: trabalhos adequados à realidade; pesquisas realizadas com condições de aplicabilidade; pesquisa é algo que estimula, proporciona personalização de assistência, maior segurança no serviço, e outras mais.

Em nosso estudo, os que referiram "dificuldades" disseram que isso decorre do pouco conhecimento em metodologia da pesquisa; com isso sentem menor chance de incorporarem a pesquisa à prática.

Outros aspectos citados são: os hospitais não dão estímulo, principalmente os públicos pela falta de pessoal, material; sobrecarga de trabalho, por ninguém estar voltado para a pesquisa; falta de compreensão por parte da chefia do serviço de enfermagem, no que se refere à liberação de horário para desenvolver pesquisa; falta de colaboração dos próprios colegas; jornada de trabalho exaustiva e sobrecarga administrativa com pre juízo à área assistencial.

Informaram também que por volta de 1964, nos "Serviços de Enfermagem na Previdência" o incentivo à pesquisa era verbal; era limitada em decorrência da falta de pessoal e faltava estímulo para que alguém se dedicasse a essa atividade e deixasse de lado suas tarefas obrigatórias.

Tais resultados têm causado desmotivação e desvalorização profissional; com isso o enfermeiro assistencial não se posiciona como profissional de nível superior deixando outros interferirem na sua profissão e colocando-se numa posição submissa.
Outros mencionaram que às vezes a dificuldade de aplicação decorre da própria escolha do tema, e que o enfermeiro leva anos para desenvolver um trabalho e quando o termina só há satisfação individual pois o trabalho acaba sendo guardado.

A própria planta física dos hospitais, enfermarias com vários doentes, fora dos padrões recomendados pelo Ministério da Saúde tem dificultado a aplicação de resultados de pesquisas. Assim, foi dito que se não for visto o todo, o conjunto das condições hospitalares, ou seja, tudo que for direcionado ao paciente terá sempre um resultado precário. Aliado a essas dificuldades, muitos enfermeiros assistenciais não têm só um emprego, o que o leva a fazer uma divisão de tempo, de tarefas com reflexos na aplicação de resultados de pesquisas.

Foram levantados aspectos internos da organização hospitalar; a dedicação de muito tempo em áreas não inerentes à enfermagem; a própria dificuldade de se pesquisar nos seus arquivos e prontuários por considerá-los obsoletos e de difícil obtenção de dados.

Tais problemas também refletem na formação dos residentes em enfermagem, pois estes referiram não ter quem os oriente adequadamente, e que ainda vêm da graduação muito dependentes, necessitando de assessoria tanto na produção como na implementação de resultados de pesquisas.

Mencionaram que os enfermeiros assistenciais ainda não estão educados para isso e, desta forma, fica difícil a aplicação de resultados de pesquisas. Sendo assim, sugerem que se ja feito um trabalho de base, de conscientização, pois as pessoas ainda estão muito irreverentes; muitos obstáculos necessitam ser contornados, tanto a nível administrativo como moral, para depois serem respeitados.

Diante de tantas dificuldades, disseram que o enfermeiro assistencial fica como "operário", não lê, estuda menos que o docente, e muitas vezes se depara com aspectos desconhecidos da prática e não pode desenvolver, escrever, dar continuidade, aplicar e até mesmo chegar a novos resultados. Com o enfermeiro docente, a situação é completamente diferente, pois ele tem maior facilidade, maior visão da teoria, por outro lado tem menor oportunidade para observar clinicamente o paciente.

Os dados por nós encontrados, referentes às dificuldades de aplicação de resultados de pesquisas no campo prático, são semelhantes aos encontrados por OL IVEIRA (1981); CASTRO et alii (1985); ROCHA (1985); NÓBREGA (1985); AL MEIDA (1985); CASSIANI (1987). Aliado a todas essas dificuldades, podemos ainda citar a relativa à divulgação do conhecimento produzido, resultados esses também citados pelos autores acima.

A questão 5. "Como você vê os resultados de suas pesquisas para a enfermagem?"'

As respostas encontradas evidenciam a satisfação devido à aplicabilidade de suas pesquisas. Referiram que, pelo fato de ser um trabalho feito em cima da prática, tem facilitado a sua aplicação e incorporação em outras unidades especializadas, e que tem até sido solicitados para orientações a colegas acerca de seus trabalhos.

Mas, encontramos também alguns que nada puderam aplicar por se afastarem da área assistencial e se dedicarem à administração. Este fato foi também cita- 
do por um colega que após retornar de um Curso de Especialização em Administração Hospitalar, na cidade de São Paulo, onde desenvolveu um trabalho na área de pediatria, não deu continuidade ao mesmo por ter mudado de área.

A questão 6. 'De que modo a chefia de sua equipe de trabalho recebeu os resultados de suas pesquisas?"

Nas suas respostas informaram que os resultados foram bem recebidos pela chefia, que demonstrou estímulo e apoio à produção de novas pesquisas, tendo mencionado ainda a necessidade da continuidade às pesquisas já realizadas, visando ao crescimento científico da enfermagem no hospital.

Outros mencionaram que se não tiverem apoio do diretor do hospital, da chefia do serviço de enfermagem e do pessoal auxiliar, nenhum trabalho individual do enfermeiro será compensado.

Alguns informaram que a sua chefia é muito fechada, que o enfermeiro assistencial desenvolve trabalhos de forma independente enquanto outros apenas notificaram, e um nos disse que a chefia em nada apoiava, mas também não impedia.

Em nossa opinião, para que o enfermeiro assistencial possa receber apoio tanto de sua chefia como da direção do hospital, colegas e pessoal auxiliar acreditamos que a pesquisa a ser desenvolvida deveria fazer parte do plano de trabalho do serviço de enfermagem e proporciona discussão junto ao pessoal envolvido com forma de motivação e interesse; caso contrário poderá haver dificuldades no envolvimento e na aplicação das pesquisas. É nosso pensamento que a escolha de temas deverá ser livre para que o profissional possa dar evasão a sua criatividade.

Uma colega citou que por volta de 1964 havia muito controle do pessoal, do horário de trabalho, e que o trabalho científico não causava preocupação à chefia de enfermagem. O enfoque maior, na época, era em relação ao ambiente, tudo deveria estar em ordem.

A questão 7. "O que você fez para motivar a sua equipe de trabalho a utilizar os resultados de sua pesquisas?'.

Para efetuar essa sistemática, mencionaram promover reuniōes e discussões tanto com o pessoal da equipe médica como de enfermagem, para sentir a mobilização do pessoal, desenvolvendo assim um trabalho de base para exposição dos seus resultados, e com isso conseguir credibilidade.

Citaram que antes da redação e conclusão final do trabalho, o mesmo deveria ser levado à chefia para ser submetido ao estudo dos colegas, para receber sugestões e observações, para posteriormente ser transformado em norma de serviço de enfermagem.

Tivemos também colegas que nada fizeram pela indiferença com que a chefia recebeu o resultado de sua pesquisa.

Assim, a esse respeito, LIKERT \& LIPPITT (1974) referiram que "a participação em plane jamento e interpretação se as pessoas não estão familiarizadas com o projeto de pesquisa e sabem pouco a seu respeito, estarão sujeitos a não compreender os resultados ou a não se interessar por suas aplicações. O envolvimento pessoal não somente diminui a barreira ao uso dos dados com também aumenta a probabilidade de que os resultados se jam entendidos e aceitos. Todavia, é particularmente importante que eles produzam uma motivação positiva para aplicá-los. Este envolvimento deve incluir todos aqueles que possam influenciar a aplicação dos resultados e deve iniciar-se no próprio ponto de partida do projeto e aumentar à medida que atinja a fase de análise. Esperar até que os resultados estejam disponíveis, antes de tentar obter uma participação, representa uma falha e provavelmente conduzirá à rejeição total ou parcial dos resultados".

A última questão apresentda, de número 8. "Que sugestões você daria a respeito da aplicação de resultados de pesquisa do enf ermeiro assistencial".

As respostas a essas questões foram: necessidade de ajuda; apoio; motivação; disponibilidade de recursos humanos, materiais e financeiros; liberação para cursos, encontros; escrever e ler mais; acreditar nas pesquisas; ter menor controle no horário para desenvolver pesquisas. Tudo isso tem tolhido a produção científica e a aplicação de resultados de pesquisas, além de gerar ansiedades.

Acreditam que a chefia de enfermagem e mesmo a direção do hospital devam olhar mais de perto para o problema, pois é através da pesquisa que vamos conseguir a definição no campo científico, porque não adianta termos idéias novas e não termos condições para produzi-las e/ou aplicá-las.

Informaram também que o enfermeiro assistencial deve sempre procurar atualizar-se e aplicar as técnicas aprendidas nos cursos, encontros e outros.

Foi sugerido que a chefia do serviço de enfermagem deveria sortear um enfermeiro e um funcionário de nível médio para fazer curso com flexibilidade no horário de trabalho. Atualmente a liberação favorecida pela chefia tem gerado insatisfação entre os colegas, com sérios reflexos na pesquisa tanto na sua produção como na aplicação.

Assim, sugeriram que tanto o diretor do hospital como a chefia do serviço de enfermagem devem estar voltados para o aspecto científico da enfermagem e que toda a ansiedade decorrente de tais problemas impede que o enfermeiro faça um trabalho diferente da rotina que também é importante, e não se deve saber apenas se o paciente recebeu a medicação, se seus sinais vitais estão normais, se ele foi para a sala de operações, mas ter um grupo, dentro do próprio hospital, voltado para a produção e aplicação de resultados de pesquisas.

Por outro lado, acreditam que eles devem se preocupar com esse aspecto, pois muitas vezes o enfermeiro assistencial está prestando cuidado em campo e não pensa ser este cuidado tão significativo, podendo o mesmo ser transformado num trabalho de pesquisa.

Citaram que para aplicar sua pesquisa o enfermeiro deve ter boa vontade; coragem; colaboração da chefia, da instituição, dos colegas e do pessoal auxiliar, pois não é só fazer a pesquisa e deixá-la no papel; deve-se lutar para que todos a aceitem e lhe dêem apoio.

Finalizando, o enfermeiro assistencial ao prestar cuidado ao paciente deve estar em contato periódico com a literatura, pois ele não pode se basear apenas no que aprendeu na escola; tem sempre que acompanhar as pesquisas, caso contrário cumprirá apenas a rotina, esquecendo-se e deixando de lado uma série de conhecimentos. 


\section{CONSIDERAÇÕES FINAIS}

Ao desenvolvermos o presente trabalho, acreditamos ter atingido os objetivos por nós estabelecidos, aliado a isso, a técnica da coleta de dados utilizada favoreceu nosso contato pessoal com o enfermeiro assistencial para questionar a aplicação de resultados de pesquisas na sua prática, onde obtivemos resultados altamente significantes.

Ao analisarmos os resultados, preferimos apresentá-los de forma descritiva e qualitativa, de acordo com a seqüência do roteiro das questões da entrevista pois nosso maior interesse estava relacionado à descoberta de fatos, melhor conhecimento do fenômeno a ser estudado, para desenvolvermos um estudo mais profundo no futuro.

\section{REFERÊNCIAS BIBLIOGRÁFICAS}

1 ALMEIDA, M. H. de. O conhecimento dos(as) enfermeiros(as) sobre resultados de pesquisa em enfermagem. In: 40 SEMINÁRIO NACIONAL DE PESQUISA EM ENFERMAGEM, São Paulo, ABEn-CEPEn, set. 2-5, 1985. p. 243-59.

2 BARNETT, D. E. Do nurses read? Nurse manager and nursing research reports. Nurs. Times. 77(50):2131-4, Dec., 1981.

3 CASSIANI, S. H. de B. A coleta de dados nas pesquisas em enfermagem. Estratégias, validade e confiabilidade. Ribeirão Preto, USP/Escola de Enfermagem, 1987. 156p. Dissertação (mestrado).

4 CASTRO, I. B. et alii. Dificuldades na incorporação dos resultados de pesquisa na prática da enfermagem. In: 4 SEMINÁRIO NACIONAL DE PESQUISA EM ENFERMAGEM, São Paulo, ABEn-CEPEn, set. 2-5, 1985. p. 193-242.

5 CIANCIARULlO, T. I. Prioridades e limitações da pesquisa em enfermagem no país: painel. In: SEMINÁRIO
NACIONAL DE PESQUISA EM ENFERMAGEM, Ribeirão Preto, ABEn-CEPEn, nov. 20-22, 1979, p. 107-15.

6 KETEFIAN, S. Application of selected nursing research findings into nursing practice. Nurs. Res., 24(2):89-92, mar./apr., 1975.

7 KRUEGER, J. C. Utilization of nursing research: the planning process. J. Nurs. Admin., 8(1):6-9, jan., 1978.

8 LIKERT, R. \& LIPPITT, R. A utilização da ciência social. In: FESTINGER, L. \& KATZ, D. - A pesquisa na psicologia social. Rio de Janeiro, Fundação Getúlio Vargas, 1974. p. 557-620.

9 LOPES, C. M. A produção dos enf ermeiros assistenciais em relação à pesquisa em enfermagem, em con munićpio paulista. Ribeirão Preto, USP/Escola de Enfermagem, 1983. 133 p. Dissertação (mestrado).

10 NÓBREGA, M. do R. S. Mecanismos facilitadores para a utilização da pesquisa na prática da enfermagem e para divulgação dos resultados das pesquisas realizadas. In: 4 SEMINÁRIO NACIONAL DE PESQUISA EM ENFERMAGEM, São Paulo, ABEn-CEPEn, set. 2-5, 1985, p. 260-69.

11 NOTTER, L. E. The editors report - January 1973. Nurs. Res., 22(1), 1973.

12 OLIVEIRA, M. I. R. de. O enfermeiro e a enfermagem. In: CONGRESSO BRASILEIRO DE ENFERMAGEM, 33, Manaus, ago. 2-7, 1981. Anais. Brasília, ABEn, 1981. p. 19-31.

13 Discurso de encerramento. In: 40 SEMINÁRIO NACIONAL DE PESQUISA EM ENFERMAGEM. São Paulo, set. 2-5, 1985. p. 279-80.

14 PADILLA, G. V. Incorporating research in a service sitting. J. Nurs. Admin., 9(1):44-9, jan., 1979.

15 ROCHA, M. L. de Q. Reflexões sobre a posição do pesquisador e da comunidade frente aos resultados da pesquisa de enfermagem, In: 4 SEMINÁRIO NACIONAL DE PESQUISA EM ENFERMAGEM, São Paulo, ABEn-CEPEn, set. 2-5, 1985. p. 143-51.

\section{Tribuna do Leitor A REBEn ABRIU ESPAÇO PARA SUA OPINIÃO. MÃOS À OBRA!}

